\title{
Production and characterization of a monoclonal antibody against the sialidase of Gardnerella vaginalis using a synthetic peptide in a MAP8 format
}

\author{
Karen Cortés-Sarabia ${ }^{1} \cdot$ Cynthia Rodríguez-Nava $^{1} \cdot$ Yolanda Medina-Flores ${ }^{2} \cdot$ Olga Mata-Ruíz $^{2} \cdot$ Joel E. López-Meza $^{3}$. \\ Miying Dessire Gómez-Cervantes ${ }^{1}$ • Isela Parra-Rojas ${ }^{1}$ - Berenice Illades-Aguiar ${ }^{1}$. Eugenia Flores-Alfaro ${ }^{1}$. \\ Amalia Vences-Velázquez ${ }^{1}$
}

Received: 27 March 2020 / Revised: 7 May 2020 / Accepted: 17 May 2020 / Published online: 27 May 2020

(C) Springer-Verlag GmbH Germany, part of Springer Nature 2020

\begin{abstract}
Bacterial vaginosis is one of the most frequent vaginal infections. Its main etiological agent is Gardnerella vaginalis, which produces several virulence factors involved in vaginal infection and colonization, in particular, sialidase (SLD), a potential clinical biomarker that participates in immune response modulation and mucus degradation. The main objective of this work was the production and evaluation of a monoclonal antibody against $G$. vaginalis sialidase and its validation in immunoassays. For immunization of mice, a synthetic multiantigenic peptide was used, and hybridomas were generated. After fusion, hybridomas were evaluated for antibody production and cloned by limited dilution. One clone producing IgG1 was selected and characterized by indirect ELISA, dot blot, and Western blot, and we also tested clinical isolates and HeLa cells infected with G. vaginalis. The results showed that the anti-SLD antibody recognized a single protein of $\sim 90 \mathrm{kDa}$ that correlated with the estimated molecular weight of SLD. In addition, anti-SLD antibody recognized SLD from complete bacteria and from culture supernatants of infected Hela cells. In conclusion, our results showed that the anti-SLD antibody recognized SLD from different sources and could be considered a new tool for the diagnosis of bacterial vaginosis.
\end{abstract}

\section{Key Points}

- Anti-sialidase $m A b$ was generated using a synthetic peptide

- The mAb recognizes synthetic peptide and intact protein from multiple sources

- The antibody was characterized by several immunological methods

Keywords Gardnerella vaginalis $\cdot$ Sialidase $\cdot$ Monoclonal antibody $\cdot$ Bacterial vaginosis

Amalia Vences-Velázquez

ameliavences.v@uagro.mx

1 Facultad de Ciencias Químico Biológicas, Universidad Autónoma de Guerrero, Chilpancingo, Guerrero, Mexico

2 Laboratorio de Anticuerpos Monoclonales, Instituto de Diagnóstico y Referencia Epidemiológicos "Dr. Manuel Martínez Báez", Francisco de P. Miranda 177, Lomas de Plateros, 01480 Ciudad de México, Mexico

3 Centro Multidisciplinario de Estudios en Biotecnología, Facultad de Medicina Veterinaria y Zootecnia, Universidad Michoacana de San Nicolás de Hidalgo, Morelia, Michoacán, Mexico

\section{Introduction}

Bacterial vaginosis $(\mathrm{BV})$ is one of the most common vaginal infections that affects women of reproductive age, with an estimated global prevalence of approximately 20-60\%, and involves substitution of the normal microbiota by anaerobic bacteria (Bautista et al. 2016). The clinical symptomatology includes white or gray vaginal discharge and a "fishy" vaginal odor caused by the presence of volatile amines, such as cadaverine, putrescine, and trimethylamine; however, half of infected women present no symptoms (Kerubo et al. 2016). The associated complications of BV include pelvic inflammatory disease, membrane rupture, low newborn birth weight in pregnant women (Hillier et al. 1995), and an increase in 
susceptibility to the acquisition of sexually transmitted diseases, such as chlamydia, trichomonas, herpes virus, human immunodeficiency virus, and human papilloma virus (Buve et al. 2014; Gillet et al. 2011; Hay 2017; Sweet 2000; Thurman et al. 2015). BV diagnosis is based on clinical symptomatology and cellular morphology observed in patients; among these, the Amsel (Amsel et al. 1983) and Nugent (Nugent et al. 1991) criteria are the most used.

Gardnerella vaginalis, the main etiological agent of BV, produces virulence factors associated with the invasion and colonization of the vaginal tract, such as vaginolysin, biofilm formation, prolidase, sialidase (SLD), among others, that are associated with the clinical outcomes observed in BV (Cauci et al. 2008; Patterson et al. 2010). The SLD is an enzyme that cleaves terminal sialic acid residues from human glycans (Lewis et al. 2013) and is associated with tissue destruction, bacterial invasion, immune response evasion, and obtaining of nutrients related to bacterial growth (Cauci et al. 2002; Cauci and Culhane 2011; Lewis et al. 2012). In addition to $G$. vaginalis, SLD is also produced by several BVassociated microorganisms, such as Prevotella, Bacteroides, and Mobiluncus (Briselden et al. 1992; Schellenberg et al. 2016; Smayevsky et al. 2001).

Due to the importance of SLD during invasion and colonization of the vaginal tract, it has been proposed as a biomarker for BV diagnosis. Previous studies have shown that high levels of SLD are associated with BV cases, in comparison with the low levels found in healthy women (Briselden et al. 1992; Cauci et al. 1998; Marconi et al. 2013). The most widely used techniques for SLD determination involve enzymatic evaluation using 2-(4-methylumbelliferyl)-d-Nacetylneuraminic acid (MUAN) as a substrate (Marconi et al. 2013) or a rapid test termed BVBlue (Gryphus Diagnostics, LLC) (Myziuk et al. 2003). In spite of this, the generation of new biological products to evaluate the roles of SLD during BV development and the standardization of new diagnostic techniques based on antigen-antibody reactions are needed, which could improve the diagnostic sensitivity and specificity. Taking into account all of the above-mentioned, the aim of this study was the production and characterization of a monoclonal antibody directed against $G$. vaginalis SLD.

\section{Materials and methods}

\section{Gardnerella vaginalis strain}

The Gardnerella vaginalis ATCC 14018 (ATCC® 14018 strain was used, which was donated kindly by Graciella Castro-Escarpulli. The strain was grown in Columbia agar supplemented with $10 \%$ of human blood (from a healthy donor with previous consent), and the main morphological characteristic includes Gram-negative coccobacillus, negative oxidase and catalase, and positive hydrolysis of hippurate.

\section{Peptide selection}

For peptide design, we downloaded the reference sequence (WP_004132912.1) of G. vaginalis SLD from the NCBI protein database. The peptide was designed based on in silico analysis performed with the software ABCpred (Saha and Raghava 2006) (http://crdd.osdd.net/raghava/abcpred/) and predicted antigenic peptides (Kolaskar and Tongaonkar 1990) (http://imed.med.ucm.es/Tools/antigenic.pl). The peptide was selected according to its predicted characteristics of immunogenicity and antigenicity (necessary for immune response induction). The peptide was ten amino acids in length and included a portion of the amino terminal region of SLD. Peptide synthesis in multiantigenic peptide 8 (MAP8) format was performed by PepMic (http:// www.pepmic.com/) and dissolved to a final concentration of 1 $\mathrm{mg} / \mathrm{mL}$ and named SLD-MAP8.

\section{Monoclonal antibody production}

Hybridomas were generated as previously described (Köhler and Milstein 1975). Eight-week-old female BALB/c mice were immunized weekly with $30 \mu \mathrm{g}$ of the SLD-MAP8 peptide using Freund's complete and incomplete adjuvants (Sigma-Aldrich Cat \# F5881 and Cat \# F5506). Hybrid generation was performed as previously described by our workgroup (Cortés-Sarabia et al. 2019). Culture supernatant samples were monitored by indirect enzyme-linked immunosorbent assay (ELISA) using SLD-MAP8 peptide as antigen, and hybridomas secreting monoclonal antibodies (mAb) were subcloned twice by limiting dilution and maintained in DMEM cell culture medium (Sigma-Aldrich Cat \# D5796) with $10 \%$ fetal bovine serum (FBS, Gibco Cat \# 16000044) and antibiotics.

\section{Polyclonal antibody production}

For a positive control, we employed polyclonal antibodies (pAbs) against the complete bacteria. We immunized a New Zealand rabbit with the complete inactivated bacteria using the $G$. vaginalis ATCC 14018 as an immunogen. The rabbit was immunized subcutaneously using complete (Life technologies Cat \# P1503) and incomplete Freund's (Sigma-Aldrich Cat \# F5506) adjuvants. The resultant hyperimmune serum was diluted 1:500 in all experiments performed in this work.

\section{$m A b$ and $p A b$ purification}

For quantitative analysis, mAbs and pAbs were purified from cell culture medium and rabbit serum, respectively, using 
protein A sepharose Cl-4B (GE Life Sciences Cat \# GE170963-03) following manufacturer's instructions. Purified IgG $(\mathrm{mg} / \mathrm{mL})$ concentrations were determined by measuring OD at $280 \mathrm{~nm}$ in a microplate reader (BioTek Epock).

\section{Enzyme-linked immunosorbent assay}

Evaluation of immune responses in the immunized mice, hybrid selection, mAb immunoglobulin class, SLD recognition in $\mathrm{HeLa}$ cells, antigens, and $\mathrm{mAb}$ titration was determined by indirect ELISA. Microtiter plates (Sigma-Aldrich Cat \# CLS3590) were coated with the antigen (SLD-MAP8, HeLa cell culture supernatant, or samples of $G$. vaginalis) by adding $100 \mu \mathrm{L}$ of protein solution in a coating buffer $\left(50 \mathrm{mM} \mathrm{Na} \mathrm{CO}_{3} / \mathrm{NaCO}_{3} \mathrm{H}\right.$, $\mathrm{pH}$ 9.6) and incubated overnight at $4{ }^{\circ} \mathrm{C}$. Plates were blocked for $30 \mathrm{~min}$ at room temperature (RT) in $200 \mu \mathrm{L}$ of $5 \%$ skimmed milk in PBS-Tween $(0.05 \%)$ and then incubated with serum, culture supernatant or purified $\mathrm{mAb}$ for $2 \mathrm{~h}$ at $37^{\circ} \mathrm{C}$. After washing, the plates were incubated with $100 \mu \mathrm{L}$ (dilution $1: 2,000$ ) of anti-mouse $\mathrm{H}+\mathrm{L}$ (heavy + light) (Jackson ImmunoResearch Cat \# 115-035-003), anti-Mu (Jackson ImmunoResearch Cat \# 115-035-020), anti-gamma (Jackson ImmunoResearch Cat \# 115-035-164), anti-IgG1 (Cat \# SAB3701169), anti-IgG2a (Sigma-Aldrich Cat \# SAB3701178), anti-IgG2b (Sigma-Aldrich Cat \# 3701185), or anti-IgG3 (Sigma-Aldrich Cat \# SAB3701192) coupled to HRP (horseradish peroxidase) (except IgG1 for which we used protein A coupled to HRP for detection), diluted in $0.05 \%$ PBSTween and incubated for $2 \mathrm{~h}$ at $37^{\circ} \mathrm{C}$. The enzymatic reaction was developed using O-phenylenediamine dyhydrochloride (Sigma-Aldrich Cat \# P1526) and terminated with $2 \mathrm{~N} \mathrm{H}_{2} \mathrm{SO}_{4}$. The optical density was measured at $492 \mathrm{~nm}$ in a microplate reader (Tecan Sunrise).

\section{Protein precipitation from G. vaginalis culture supernatant}

We added $1 \mathrm{~mL}$ of acetone to $500 \mu \mathrm{L}$ of $G$. vaginalis culture medium, and the solution was mixed and incubated for $1 \mathrm{~h}$ at $-20{ }^{\circ} \mathrm{C}$. Next, the tube was centrifuged for $15 \mathrm{~min}$ at 14,000 rpm, and the supernatant was discarded. The obtained pellet was dried at room temperature and resuspended in $30 \mu \mathrm{L}$ of PBS.

\section{Western and dot blots}

For Western blotting, $20 \mu \mathrm{g}$ of the total protein lysate from G. vaginalis ATCC 14018 strain was denatured in a loading buffer at $98{ }^{\circ} \mathrm{C}$ for $10 \mathrm{~min}$ (Biorad Cat \# 1610747), then separated by $12 \%$ SDS-PAGE, and transferred to a nitrocellulose membrane (Biorad Cat \# 1620115). Membranes were blocked with $5 \%$ skim milk in $0.05 \%$ PBS-Tween for
Fig. 1 Immune response evaluation and anti-SLD clones.

(a) Immune response evaluation in selected mice. Indirect ELISA using as primary antibody the collected serum during the immunization process. As a secondary antibody, we used an anti-H + L antibody. (b)

Evaluation of clones obtained after fusion. Indirect ELISA using as primary antibody the culture supernatant of the evaluated clones in order to determine the immunoglobulin class produced by each clone. We used specific antibodies against the mu and gamma chains. (c) and (d) Representative images of the hybridomas produced a

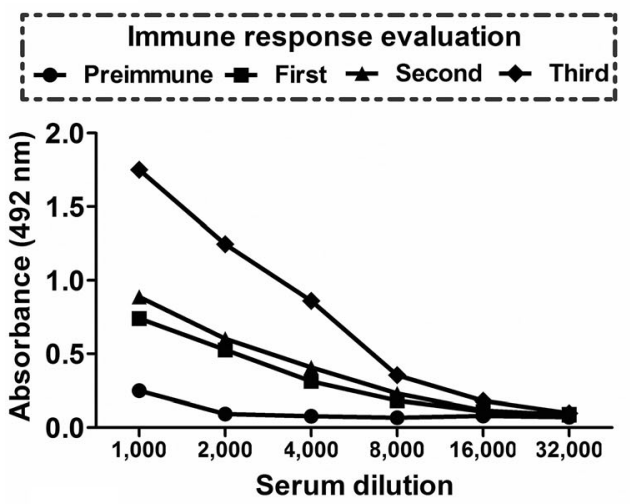

C

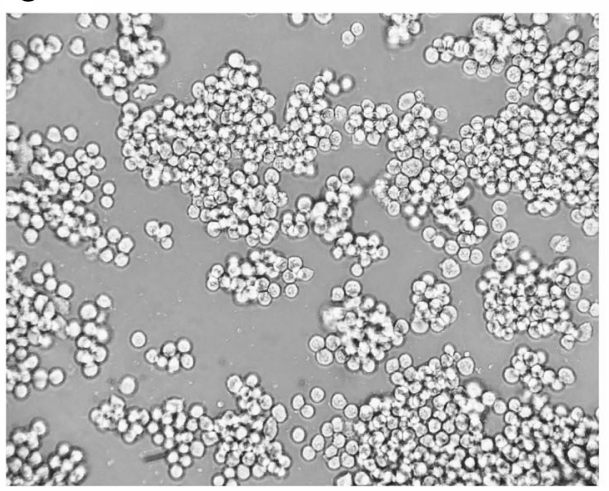

b



d

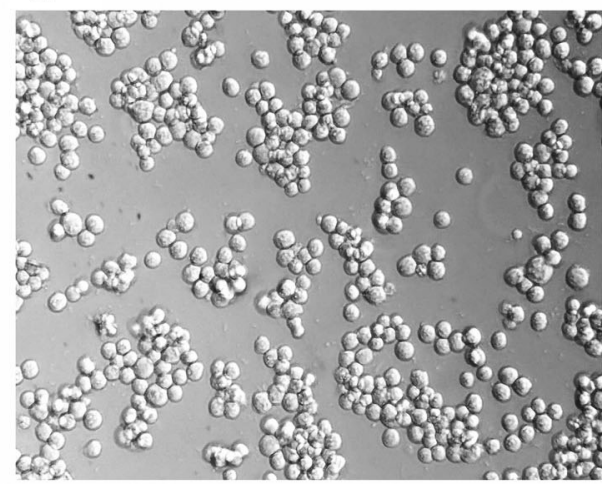


40 min at RT with shaking. After washing, the membrane was incubated with $\mathrm{mAbs}$ at a final concentration of $10 \mu \mathrm{g} / \mathrm{mL}$ at room temperature and with constant agitation for $2 \mathrm{~h}$, followed by incubation with HRP-conjugated anti-mouse IgG antibody (dilution 1:2000), or anti-rabbit IgG antibody (dilution $1: 4000$ ) in $0.05 \%$ PBS-Tween, for $2 \mathrm{~h}$. Immunoreactivity was developed with 3-3'-diaminobenzidine (DAB, SigmaAldrich Cat \# D8001). Dot blots similarly used total protein lysates, complete bacteria, or culture supernatant immobilized on nitrocellulose membranes.

\section{Isolation and culture of $G$. vaginalis}

Isolation of $G$. vaginalis from clinical samples was performed on Columbia agar supplemented with $10 \%$ human blood and the selective agent SR119RE (OXOID Cat \# 1441974). Vaginal swab samples were inoculated and incubated at 37 ${ }^{\circ} \mathrm{C}$ under a $5 \% \mathrm{CO}_{2}$ atmosphere for $24 \mathrm{~h}$. Microbial identification was performed by Gram staining and catalase and oxidase negative reactions. Isolated bacteria were inoculated in thioglycollate broth and incubated at $37^{\circ} \mathrm{C}$ in $5 \% \mathrm{CO}_{2}$ atmosphere for $24 \mathrm{~h}$. Broth cultures were used for biotyping tests and dot blot experiments.

\section{Biotyping}

Biotyping was performed based on the classification scheme proposed by Piot et al. (1984). Hippurate hydrolysis: $100 \mu \mathrm{L}$ of the broth culture was inoculated into an aliquot containing $400 \mu \mathrm{L}$ of $1 \%$ sodium hippurate reagent (Sigma-Aldrich Cat \# $\mathrm{H} 9380$ ), which was incubated at $37^{\circ} \mathrm{C}$ for $2 \mathrm{~h}$ and then $200 \mu \mathrm{l}$ of ninhydrin (Sigma-Aldrich Cat \# 151173) was added and the solution homogenized. The test was interpreted as positive when the medium turned purple, indicating the presence of glycine in the mixture as a result of hippurate hydrolysis, and negative when the reagent did not change color. $\beta$ Galactosidase activity was determined using $100 \mu \mathrm{L}$ of the broth culture inoculated into an aliquot of the 2nitrophenyl- $\beta$-D-galactopyranoside reagent (Sigma-Aldrich Cat \# N1127) and incubated at $37{ }^{\circ} \mathrm{C}$ for $24 \mathrm{~h}$. The test was interpreted as positive when the reagent in the tube turned yellow, indicating the presence of O-nitro phenol formed by the action of $\beta$-galactosidase, which indicates that the bacteria had metabolized lactose, and the test was interpreted as negative when the reagent did not change color. The production of lipase was evaluated according to the method described by Moncla and Pryke (2009). Bacteria were inoculated on egg yolk agar and incubated at $37^{\circ} \mathrm{C}$ for $24 \mathrm{~h}$, and the presence of
Fig. 2 Anti-SLD mAb. (a) Immunoglobulin class and subclass produced by the $1 \mathrm{H} 12$ clone. As primary antibody, we used the culture supernatant of clone $1 \mathrm{H} 12$, mouse hyperimmune serum $(\mathrm{C}+)$, and no hyperimmune serum $(\mathrm{C}-)$. As secondary antibodies, we used specific antibodies against different classes ( $\operatorname{IgM}$ and $\operatorname{IgG}$ ) and subclasses (IgG1, IgG2a, IgG2b, and IgG3). (b) Anti-SLD mAb purification evaluation. $12 \%$ SDS-PAGE and Coomassie blue staining. MWM, molecular weight marker; HC, heavy chain; LC, light chain. (c) and (d) Antibody and antigen titration. Indirect ELISA using decreasing concentrations of antigen and purified antibody by double dilution. As primary antibody, we used purified $1 \mathrm{H} 12$ antibody, and as secondary antibody, an anti-H $+\mathrm{L}$ antibody was used
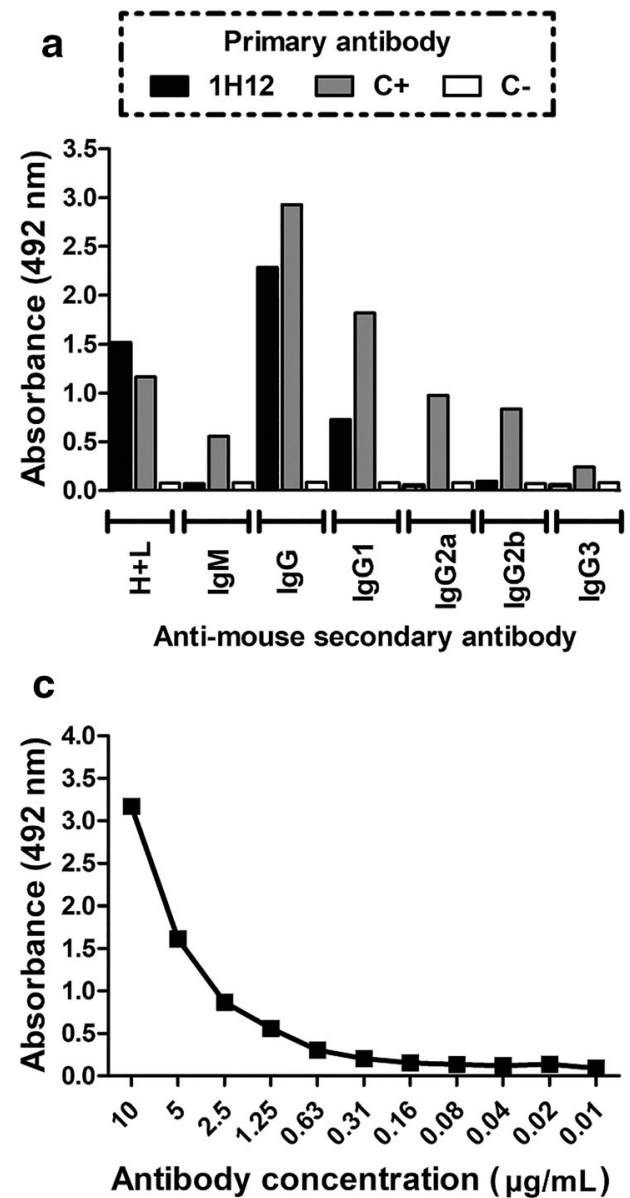

b

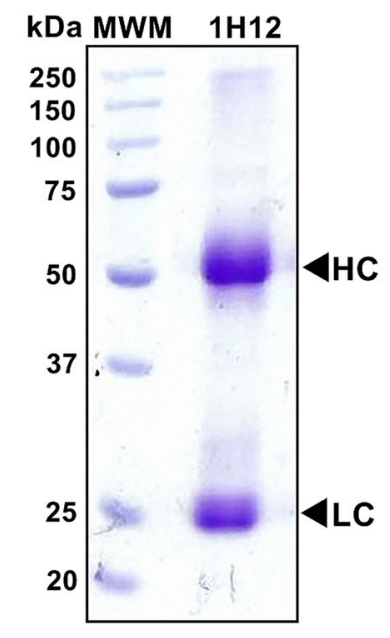

d

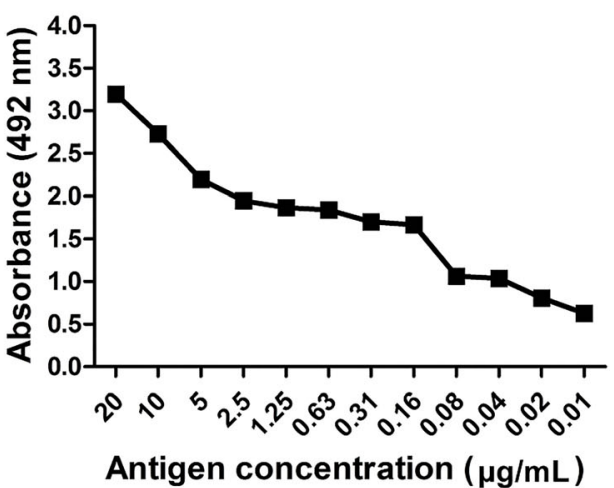


an iridescent halo surrounding the colonies was considered as a positive result, and the absence of this halo as negative.

For the analysis of SLD expression in the clinical samples using dot blots, we used ImageJ software (Schneider et al. 2012) to perform a qualitative analyses of each blot, and considered the IntDent (integrated density) of each sample as crude data. Background subtraction was performed for each sample for data homogenization using a negative control.

\section{G. vaginalis culture and growth kinetics}

G. vaginalis ATCC 14018 strain was cultured anaerobically at $37{ }^{\circ} \mathrm{C}$ in $5 \% \mathrm{CO}_{2}$ for $24 \mathrm{~h}$ in Trypticasein Soy Agar (TSA) (Becton, Dickinson and Company, Sparks MD, USA). To establish the growth kinetics of G. vaginalis, a bacterial colony was inoculated into $5 \mathrm{~mL}$ of brain heart infusion broth (BHI) (Becton, Dickinson and Company, Sparks MD, USA), and incubated at $37^{\circ} \mathrm{C}$ with $5 \%$ of $\mathrm{CO}_{2}$ and $180 \mathrm{rpm}$ agitation, overnight. Next, OD was adjusted to 0.2 (equivalent to $15 \times 10^{6} \mathrm{CFU} / \mathrm{mL}$ ) and finally, $50 \mathrm{~mL}$ of BHI broth was inoculated in triplicate with $10 \mathrm{~mL}$ of the OD-adjusted bacteria. Bacterial growth was monitored at 0.5, 1, 2, 4, 8, 10, 12, 24, 36, 48, and $72 \mathrm{~h}$. Absorbance was measured at $595 \mathrm{~nm}$ in a spectrophotometer (Bio Rad iMark), and non-inoculated broth was used as a negative control.

\section{SLD production during growth of $G$. vaginalis}

SLD production in bacterial cultures was evaluated using $\mathrm{mAb}$ and an indirect ELISA method. For this, the bacteria (1:200 dilution), culture supernatants, and complete bacteria of each monitored time point $(0.5$ to $72 \mathrm{~h})$ were fixed in 96-well plates for $2 \mathrm{~h}$ at $37{ }^{\circ} \mathrm{C}$ and then blocked with 5\% skim milk (BD Difco Cat \# 232100) in PBSTween during $30 \mathrm{~min}$ at $37{ }^{\circ} \mathrm{C}$. Anti-SLD mAb was used at $10 \mu \mathrm{g} / \mathrm{mL}$, and anti-mouse HRP-coupled IgG diluted a

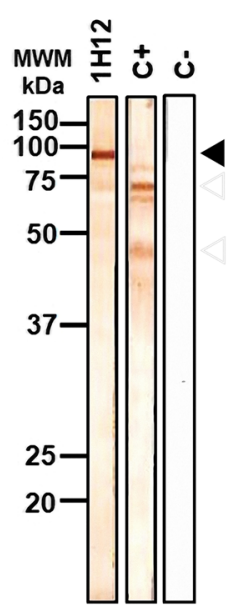

C

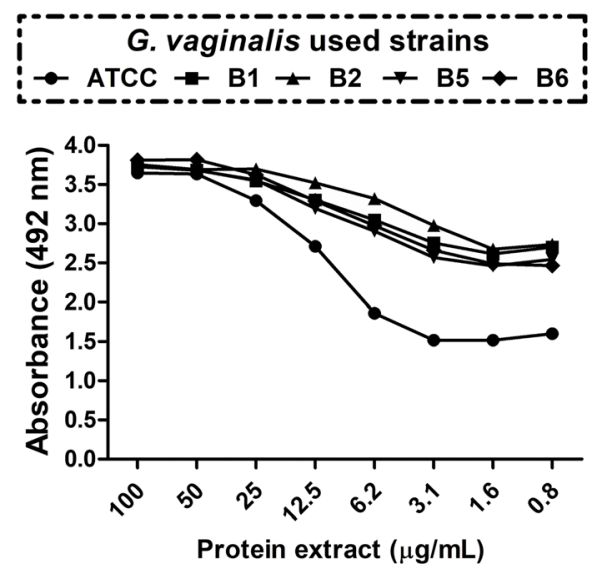

Fig. 3 Preliminary characterization of $1 \mathrm{H} 12$ anti-SLD mAb. (a) and (b) Western blot and dot blot analyses. We used total lysates, complete bacteria, or culture supernatants of $G$. vaginalis ATCC 14018 strain and clinical isolates of biotypes 1, 2, 5, and 6 as antigens. (c) and (d) Detection of SLD in the ATCC 14018 strain and clinically isolated biotypes of

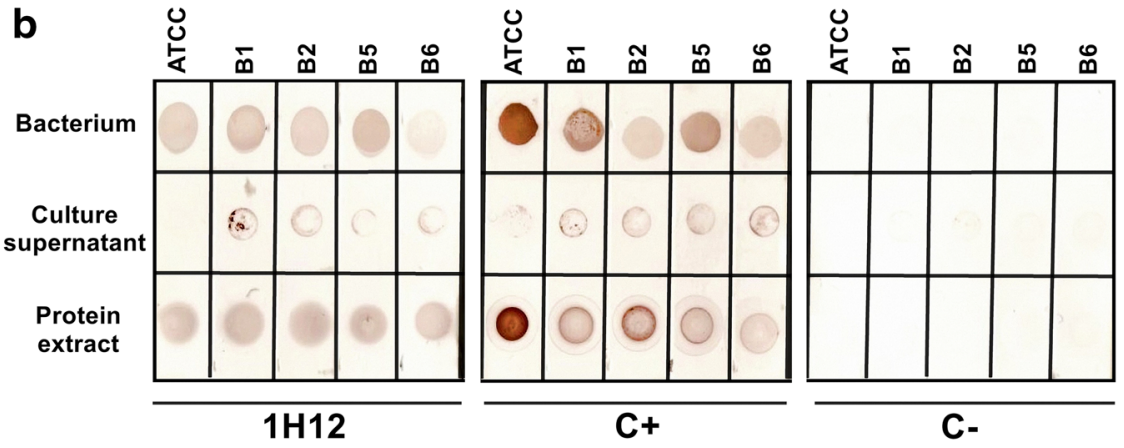

d

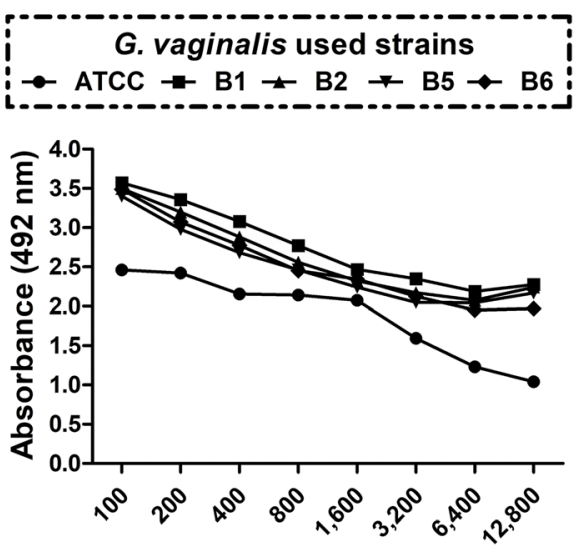

Culture supernatant protein precipitation (Dilution)

G. vaginalis. Indirect ELISA using protein total extract and proteins precipitated from the culture supernatants to evaluate antibody recognition. In all experiments, $1 \mathrm{H} 12$ anti-SLD $\mathrm{mAb}, \mathrm{C}+$ is polyclonal antibody against $G$. vaginalis and in $\mathrm{C}$ - primary antibody was omitted. As secondary antibody, an anti-H + L antibody was used 
1:2000 in PBS-Tween was used as a secondary antibody. The reaction was developed using $\mathrm{O}$ phenylenediamine dyhydrochloride (Sigma-Aldrich Cat \# P9029) and stopped with $2 \mathrm{~N}$ sulfuric acid.

\section{HeLa cell culture and infection with $G$. vaginalis}

HeLa cells (derived from a woman with cervical adenocarcinoma and HPV 18 infection) were grown on Petri dishes (Corning-Costar) in growth medium composed of DMEM/F-12 (Sigma-Aldrich Cat \# D9785) supplemented with $10 \%$ fetal bovine serum (Sigma-Aldrich Cat \# F2442), $100 \mathrm{U} / \mathrm{mL}$ penicillin, $100 \mu \mathrm{g} / \mathrm{mL}$ streptomycin (Gibco Cat \# 15140122), and $1 \mu \mathrm{g} / \mathrm{mL}$ amphotericin B (Thermo Fisher Cat \# 15290018). HeLa cells were grown under a $5 \% \quad \mathrm{CO}_{2}$ atmosphere at $37{ }^{\circ} \mathrm{C}$, and $24 \mathrm{~h}$ before infection with $G$. vaginalis, cells were cultured in serum-free medium without antibiotics. On the next day, HeLa cells were infected for 2 and $4 \mathrm{~h}$, with the following multiplicities of infection (MOI); 1:1 and 20:1 bacterium per cell $\left(15 \times 10^{6} \mathrm{CFU} / \mathrm{mL}\right)$ under $5 \%$ $\mathrm{CO}_{2}$ and at $37{ }^{\circ} \mathrm{C}$. After infection, culture supernatants were collected and used for indirect ELISAs and dot blots.

\section{Results}

First, we selected a peptide based on the results of in silico analysis considering the localization ( $\mathrm{N}$-terminal), immunogenicity, and antigenicity. The obtained SLD-MAP8 synthetic peptide was used for the immunization of five BALB/c mice. We performed immune response evaluations in all of the immunized mice. According to the results, the mouse with the highest titer was selected for hybridoma production (Fig. 1a). Subsequently, the mouse was sacrificed and spleen was used for fusion with myeloma cells for hybridoma generation (Fig. $1 \mathrm{c}$ and d). After fusion, seven different anti-SLD antibodyproducing clones were selected; six of these produced IgM antibodies, while clone $1 \mathrm{H} 12$ produced essentially IgG antibodies (Fig. 1b). Clone 1H12 was selected and named as antiSLD mAb. This clone was grown in DMEM, and anti-SLD $\mathrm{mAb}$ was obtained and used for the following experiments.

Next, the immunoglobulin class and subclass using specific antibodies were determined. The IgG antibodies produced by clone $1 \mathrm{H} 12$ belonged to the IgG1 subclass (Fig. 2a), and the purified antibody only showed the heavy and light chains of the immunoglobulin (Fig. 2b). Further characterization included the determination of optimal concentration of antibody and antigen using the SLD-MAP8 synthetic peptide. The optimal antibody concentration was $10 \mu \mathrm{g} / \mathrm{mL}$, and the antigen concentration to be detected was $\sim 0.16 \mu \mathrm{g} / \mathrm{mL}$ (Fig. $2 \mathrm{c}$ and d).

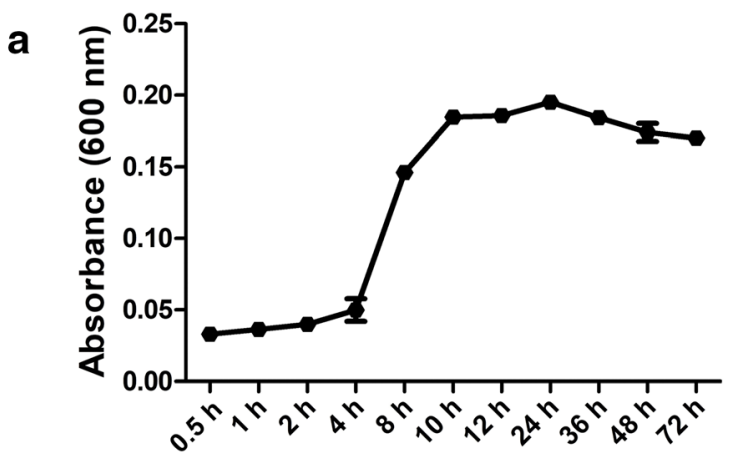

G. vaginalis growth curve evaluation

b

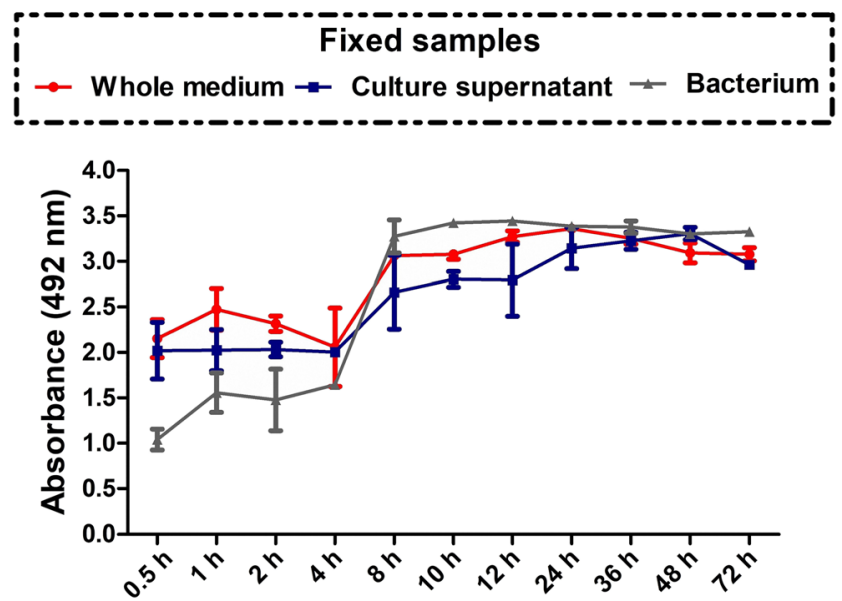

Growth curve evaluation by Indirect ELISA

Fig. 4 Evaluation of SLD recognition during growth of $G$. vaginalis (a) Growth curve of $G$. vaginalis. We used as culture medium brain heart infusion, and optical density was determined at $600 \mathrm{~nm}$ during $0.5,1,2,4$, $8,10,12,24,36,48$, and $72 \mathrm{~h}$. (b) Detection of SLD during the growth of G. vaginalis. Indirect ELISA for qualitative evaluation of the SLD present in samples of complete bacterial culture (bacteria + culture supernatant), culture supernatant, or bacteria only. As primary antibody, we used the 1H12 anti-SLD antibody and as secondary antibody, we used an anti-H + L antibody

Next, the specificity of the anti-SLD mAb was evaluated in G. vaginalis ATCC 14018 strain, to determine if the antibody could recognize the complete, intact form of SLD. By Western blot, it was determined that the anti-SLD mAb recognized the

Table 1. Clinical isolates used in this study

Diagnostic

Biotype Normal microbiota $(\%)$ Bacterial vaginosis n(\%) Total

\begin{tabular}{llll}
\hline 1 & $13(28.9)$ & $2(9.1)$ & $15(22.4)$ \\
2 & $2(4.4)$ & $4(18.2)$ & $6(9.0)$ \\
5 & $11(24.5)$ & $0(0.0)$ & $11(16.4)$ \\
6 & $19(42.2)$ & $16(72.7)$ & $35(52.2)$ \\
Total & $46(100)$ & $22(100)$ & $67(100)$ \\
\hline
\end{tabular}


complete protein in denatured form, with a single band of approximately $90 \mathrm{kDa}$ detected, which correlated with the predicted molecular weight of SLD (Fig. 3a). After this, we evaluated by dot blot SLD recognition in the complete bacteria, culture supernatant, and total protein extract using G. vaginalis ATCC 14018 strain and four clinical isolates belonging to the biotypes $1,2,5$, and 6 . Interestingly, the anti-SLD mAb not only showed high levels of recognition in the complete bacteria and protein extract but also detected SLD in the culture media of clinical isolates (Fig. 3b). To corroborate previously obtained results, we performed evaluations by indirect ELISA using total protein extract and culture supernatant, and the results were similar (Fig. 3c and d).

We speculated whether the anti-SLD mAb could be used to predict in a semi-qualitative way the amount of SLD produced by $G$. vaginalis during the different phases of bacterial growth, considering that this protein is a primary metabolite. For this, the bacteria were cultured for $72 \mathrm{~h}$ and the samples were collected at different times (Fig. 4a). We observed that after the first $30 \mathrm{~min}$, the bacteria begin to produce SLD, and the increase was proportional to the growth phase (Fig. 4b). Next, SLD production was evaluated by dot blot in 67 clinical isolates of $G$. vaginalis from women with normal microbiota $(\mathrm{NM} ; \mathrm{n}=45)$ and bacterial vaginosis $(\mathrm{BV} ; \mathrm{n}=22)$ belonging to four $(1,2,5$, and 6$)$ of the eight different $G$. vaginalis biotypes (Table 1). Results showed that the amount of SLD produced varied between isolates, and even between complete bacteria and supernatants (Fig. 5a). Using the previous blots, we analyzed in a semi-qualitative way the amount of SLD in the samples isolated from women with NM and BV, observing similar results in both groups (Fig. $5 b)$. In addition, samples were separated according to biotype; 1 $(n=15), 2(n=6), 5(n=11)$, and $6(n=35)($ Table 1$)$, and we observed that biotypes 2 and 5 secreted less SLD in comparison to biotypes 1 and 6 (Fig. 5c).
Fig. 5 SLD recognition in clinical samples. (a) and (b) Dot blot results of SLD evaluation in the complete bacteria and culture supernatants. Each dot is a different clinical sample, and we used the same sample in the same position in the complete bacteria and culture supernatants. Dot blots were performed as previously described. Negative controls: E8-9, H7-9; positive controls: E10, H10. (c) and (d) Densitometric analysis of the dot blots. The analysis was carried out using ImageJ software
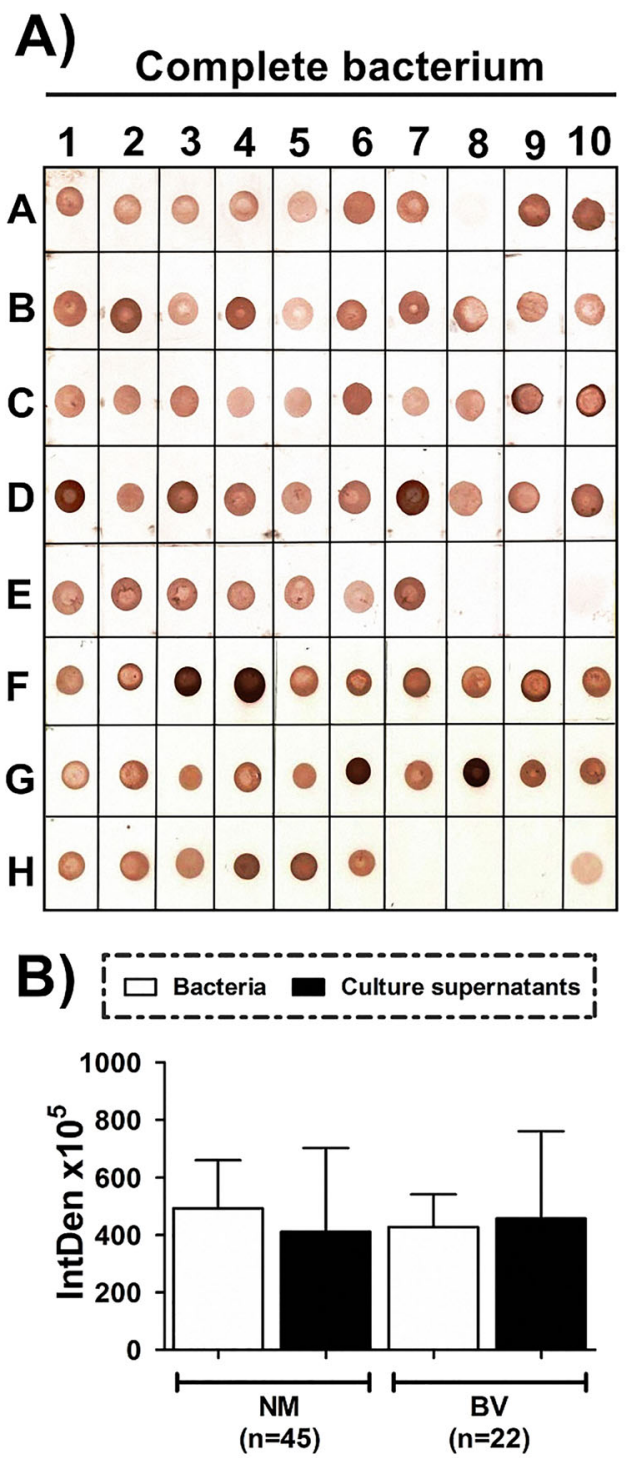

Culture supernatants

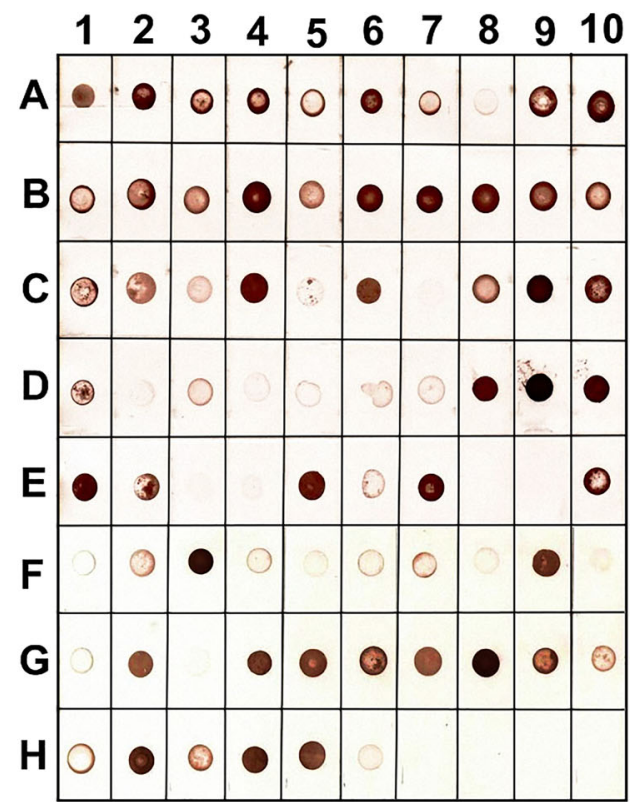

C)
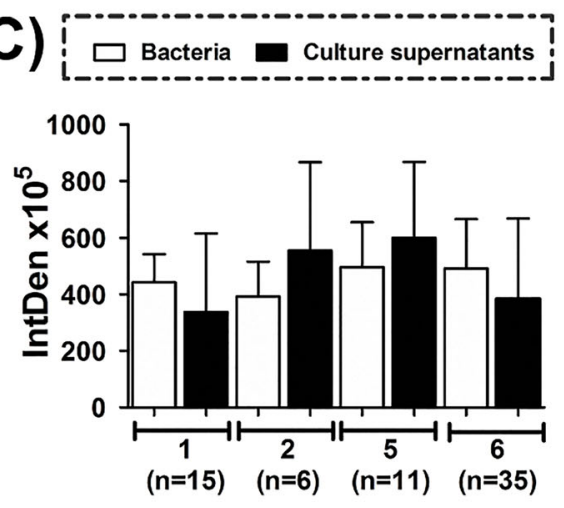

Biotypes of $G$. vaginalis 
In addition, we investigated if the anti-SLD mAb could be used for the specific detection of $G$. vaginalis in HeLa cells infected and uninfected with the bacteria in the same way as in the clinical samples. Thus, we infected HeLa cells with G. vaginalis ATCC 14018 strain with a MOI of 1 and 20 for 2 and $4 \mathrm{~h}$ and evaluated SLD in culture supernatants by ELISA and dot blot (Fig. 6a). By indirect ELISA, we did not observe recognition of SLD by anti-SLD mAb in non-infected cells, while in cells infected at MOI 1 and 20, high recognition was observed for both infection periods ( 2 and 4 h) (Fig. 6b), and similar results were observed with dot blots (Fig. 6c).

\section{Discussion}

$\mathrm{BV}$ is the main vaginal infection in woman of reproductive ages and has been associated with clinical complications that affect the quality of life (Hay 2017). The etiology of BV involves several genera of anaerobic bacteria, among them Gardnerella, Bacteroides, and Mobiluncus, which, according to previous reports, present a common virulence factor, the SLD enzyme (Briselden et al. 1992; Schellenberg et al. 2016; Smayevsky et al. 2001). SLD plays important roles in obtaining nutrients, colonization, and host immune response evasion (Harvey et al. 2001; Lewis et al. 2012; Marconi et al. 2013). Given the importance of SLD in the development of $\mathrm{BV}$, the production and characterization of a monoclonal antibody against this enzyme are necessary, which were the main objectives of this work.

Hybridomas were obtained by the immunization of mice with a synthetic multiantigenic peptide (selected from the SLD primary structure) with an eight-chain (MAP8) format. This peptide stimulated the production of antibodies that were detected in the blood of immunized mice (Fig. 1a). The MAP8
Fig. 6 Evaluation of SLD in HeLa cells infected with G. vaginalis (a) Representative images of HeLa cells infected with $G$. vaginalis. Cells were infected with a MOI (multiplicity of infection) of 1 and 20 over 2 and $4 \mathrm{~h}$. (b) Indirect ELISA and (c) Dot blot evaluation of SLD in infected HeLa cells. HPI, hours post-infection. The primary antibody used was $1 \mathrm{H} 12$, and as a secondary antibody, we used an anti-H $+\mathrm{L}$ antibody

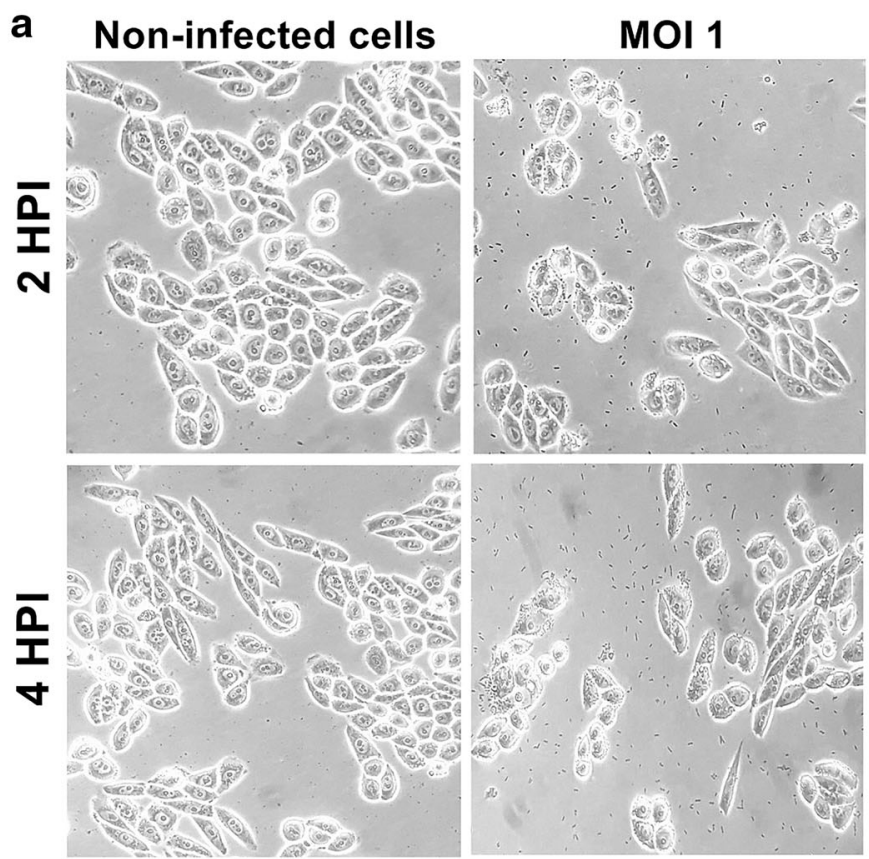

b

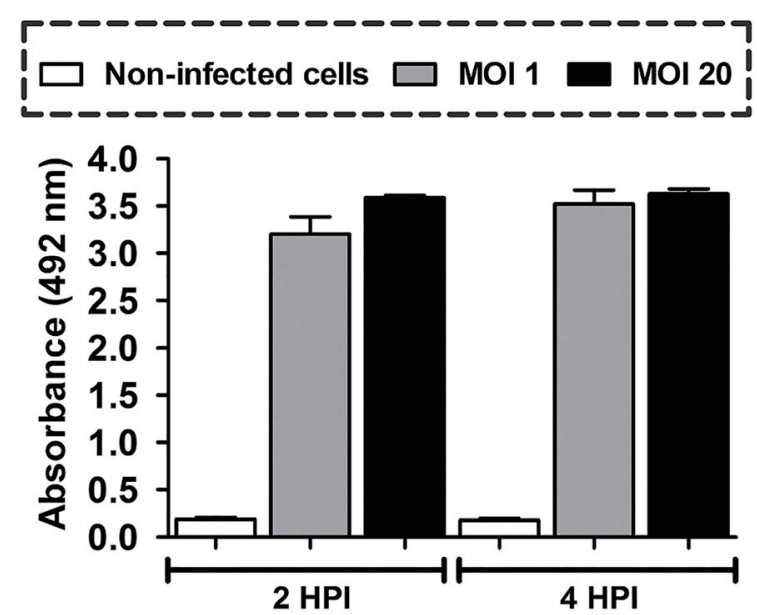

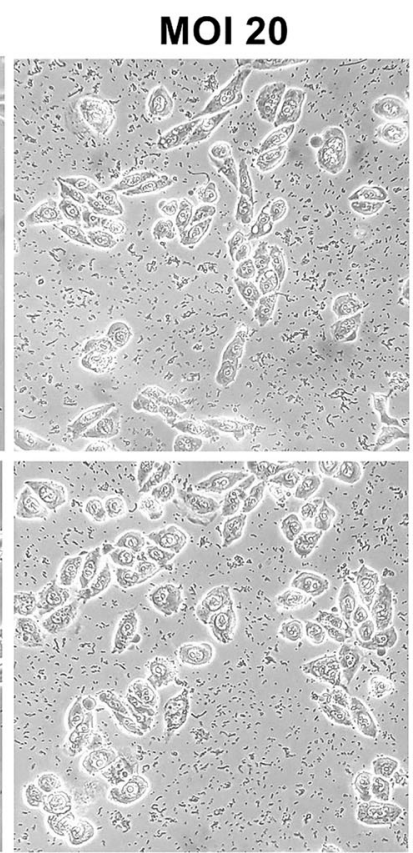

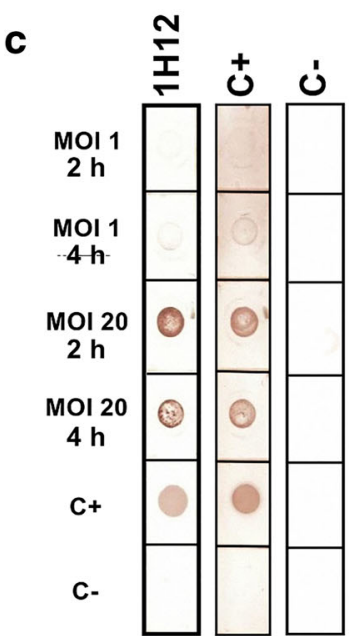


format increases the peptide size and structural complexity and allows increased antigenicity during immunization; it is also commonly used as diagnostic reagent and vaccine (Joshi et al. 2013). After fusion evaluation, seven anti-SLD producing clones were obtained (Fig. 1b). We selected clone $1 \mathrm{H} 12$ due to in vitro growth and the type of immunoglobulin class produced. IgG antibodies are commonly used in diagnostic techniques due to their structural stability and functionality after extended storage times. Also, the IgG1 subclass is the most common immunoglobulin (Vidarsson et al. 2014).

As the antibody was produced using a synthetic peptide in MAP8 format, characterization was focused on demonstrating recognition of the complete protein. We observed that the anti-SLD mAb recognized SLD under native (indirect ELISA and dot blot) and denaturing (Western blot) conditions. In Western blot, a single of band of $\sim 90 \mathrm{kDa}$ was detected, which was a preliminary indicator of the antibody specificity (Fig. 3). All of the preliminary data supported the hypothesis that the chosen sequence exposes an epitope that allows SLD identification under several conditions necessary for immunoassays. Another interesting fact is that the anti-SLD mAb showed high recognition in samples of complete bacteria and culture supernatant, which could mean that during the secretion process, SLD first is anchored to the membrane (Rodriguez-Walker and Daniotti 2017), and after being secreted, commences its function of obtaining nutrients (Lewis et al. 2013). In addition, antibody recognition of the ATCC 14018 strain and the clinical isolates provides evidence regarding the extent of conservation of the selected epitope among the different $G$. vaginalis biotypes (Figs. 3 and 5).

We investigated SLD production during bacterial growth and in infected HeLa cells. Our results showed that the synthesis of SLD commences during the first $30 \mathrm{~min}$ of culture and that protein levels were correlated with the bacteria amount and duration of infection. Previous reports revealed that SLD is considered to be a primary and secondary metabolite of $G$. vaginalis, and its production starts during the first minutes of bacterial growth and gradually increases (Cauci et al. 2005). In the preliminary analysis of SLD production in the clinical biotypes, we did not find any difference between SLD production among the biotypes, or its association with BV. One possible explanation is that the stress of cell culture could induce the production of SLD; complementary studies need to be performed to prove this hypothesis.

Finally, SLD is released by several microorganisms associated with BV besides G. vaginalis, and its activity is increased in cases of BV (Briselden et al. 1992; Cauci et al. 1998; Ferreira et al. 2015; Marconi et al. 2013), which supports the use of SLD as a potential diagnostic biomarker. However, there is a need for additional complementary experiments to evaluate $\mathrm{mAb}$ crossreactivity with other microorganisms that colonize mucosa, identify antibody affinity, and complete validation of the produced antibody according to established protocols (Bordeaux et al. 2010; Uhlen et al. 2016). Preliminary data encourage us to perform new studies to evaluate the potential clinical use of the produced $\mathrm{mAb}$ in the diagnosis of $\mathrm{BV}$ in clinical samples.

In conclusion, our data showed that the anti-SLD mAb detects SLD in complete bacteria, protein extracts, bacterial culture supernatants, and infected HeLa cells. The anti-SLD $\mathrm{mAb}$ also could be used in the standardization of new techniques for the detection of SLD in clinical samples from women with and without BV to improve early diagnosis and avoid associated complications.

Acknowledgments We are very grateful with Graciella Castro-Escapulli for the donation of Gardnerella vaginalis ATCC 14018 strain. Also, the authors thank the Laboratorio de Anticuerpos Monoclonales del InDRE and Ana Karen Estrada-Moreno for all the technical support. During this work, Miying Dessire Gomez-Cervantes (CVU: 705003), Cynthia Rodríguez-Nava (CVU: 857929), and Karen Cortés-Sarabia (CVU: 557803) received a master and doctorate scholarship from the Consejo Nacional de Ciencia y Tecnología (CONACYT).

Author contribution KCS, AVV, and YMF conceived and designed the research. KCS, CRN, OMR, JELM, and MDGC conducted the experiments. BIA, EFA, and IPR contributed new reagents and analytical tools and analyzed the obtained data. KCS, AVV, JELM, and CRN wrote the manuscript. All authors read and approved the manuscript.

Funding information This work was supported with 2018 PFCE funds granted to the academic body UAGRO CA-120.

\section{Compliance with ethical standards}

Conflicts of interest The authors declare that they have no conflict of interest.

Ethical statements The bacteria used in this study were isolated from vaginal swab samples obtained from women who had previously signed an informed consent form, according to the Helsinki Declaration of 2013, whereas blood samples were obtained from a healthy donor with previous consent. The use of both samples was approved by the ethics committee of the Dirección de Investigación of the Universidad Autónoma de Guerrero (approval no. CB-002/15). Furthermore, all procedures involving animal manipulation were performed in accordance with the bioethical regulations of the Instituto de Diagnóstico y Referencia Epidemiologica (InDRE) in Mexico City and the NOM-062-ZOO-1999.

\section{References}

Amsel R, Totten PA, Spiegel CA, Chen KC, Eschenbach D, Holmes KK (1983) Nonspecific vaginitis. Diagnostic criteria and microbial and epidemiologic associations. Am J Med 74:14-22. https://doi.org/10. 1016/0002-9343(83)91112-9

Bautista CT, Wurapa E, Sateren WB, Morris S, Hollingsworth B, Sanchez JL (2016) Bacterial vaginosis: a synthesis of the literature 
on etiology, prevalence, risk factors, and relationship with chlamydia and gonorrhea infections. Mil Med Res 3:1-10. https://doi.org/10. 1186/s40779-016-0074-5

Bordeaux J, Welsh A, Agarwal S, Killiam E, Baquero M, Hanna J, Anagnostou V, Rimm D (2010) Antibody validation. BioTechniques 48:197-209. https://doi.org/10.2144/000113382

Briselden AM, Moncla BJ, Stevens CE, Hillier SL (1992) Sialidases (neuraminidases) in bacterial vaginosis and bacterial vaginosisassociated microflora. J Clin Microbiol 30:663-666

Buve A, Jespers V, Crucitti T, Fichorova RN (2014) The vaginal microbiota and susceptibility to HIV. AIDS Lond Engl 28:2333-2344. https://doi.org/10.1097/qad.0000000000000432

Cauci S, Culhane JF (2011) High sialidase levels increase preterm birth risk among women who are bacterial vaginosis-positive in early gestation. Am J Obstet Gynecol 204:142.e1-142.e9. https://doi. org/10.1016/j.ajog.2010.08.061

Cauci S, Driussi S, Monte R, Lanzafame P, Pitzus E, Quadrifoglio F (1998) Immunoglobulin A response against Gardnerella vaginalis hemolysin and sialidase activity in bacterial vaginosis. Am J Obstet Gynecol 178:511-515. https://doi.org/10.1016/s0002-9378(98) 70430-2

Cauci S, Guaschino S, Driussi S, De Santo D, Lanzafame P, Quadrifoglio F (2002) Correlation of local interleukin-8 with immunoglobulin A against Gardnerella vaginalis hemolysin and with prolidase and sialidase levels in women with bacterial vaginosis. J Infect Dis 185:1614-1620. https://doi.org/10.1086/340417

Cauci S, McGregor J, Thorsen P, Grove J, Guaschino S (2005) Combination of vaginal $\mathrm{pH}$ with vaginal sialidase and prolidase activities for prediction of low birth weight and preterm birth. Am J Obstet Gynecol 192:489-496. https://doi.org/10.1016/j.ajog.2004. 07.023

Cauci S, Culhane JF, Di Santolo M, McCollum K (2008) Among pregnant women with bacterial vaginosis, the hydrolytic enzymes sialidase and prolidase are positively associated with interleukin1beta. Am J Obstet Gynecol 198:132.e1-132.e7. https://doi.org/ 10.1016/j.ajog.2007.05.035

Cortés-Sarabia K, Medina-Flores Y, Alarcón-Romero LDC, Mata-Ruíz O, Vences-Velázquez A, Rodríguez-Ruíz HA, Valdés J, OrtuñoPineda C (2019) Production and characterization of monoclonal antibodies against the DNA binding domain of the RE1-silencing transcription factor. J Biochem 166:393-402. https://doi.org/10. 1093/jb/mvz046

Ferreira CST, Marconi C, Parada CM d LG, Duarte MTC, Gonçalves APO, Rudge MVC, Silva MG (2015) Bacterial vaginosis in pregnant adolescents: proinflammatory cytokine and bacterial sialidase profile. Cross-sectional study. Sao Paulo Med J Rev Paul Med 133: 465-470. https://doi.org/10.1590/1516-3180.2014.9182710

Gillet E, Meys JF, Verstraelen H, Bosire C, De Sutter P, Temmerman M, Broeck DV (2011) Bacterial vaginosis is associated with uterine cervical human papillomavirus infection: a meta-analysis. BMC Infect Dis 11:10. https://doi.org/10.1186/1471-2334-11-10

Harvey HA, Swords WE, Apicella MA (2001) The mimicry of human glycolipids and glycosphingolipids by the lipooligosaccharides of pathogenic Neisseria and Haemophilus. J Autoimmun 16:257262. https://doi.org/10.1006/jaut.2000.0477

Hay P (2017) Bacterial vaginosis. F1000Research 6:1761. https://doi.org/ 10.12688/f1000research.11417.1

Hillier SL, Nugent RP, Eschenbach DA, Krohn MA, Gibbs RS, Martin DH, Cotch MF, Edelman R, Pastorek JG, Rao AV (1995) Association between bacterial vaginosis and preterm delivery of a low-birth-weight infant. The Vaginal Infections and Prematurity Study Group. N Engl J Med 333:1737-1742. https://doi.org/10. 1056/NEJM199512283332604

Joshi VG, Dighe VD, Thakuria D, Malik YS, Kumar S (2013) Multiple antigenic peptide (MAP): a synthetic peptide dendrimer for diagnostic, antiviral and vaccine strategies for emerging and re-emerging viral diseases. Indian J Virol 24:312-320. https://doi.org/10.1007/ s13337-013-0162-z

Kerubo E, Laserson KF, Otecko N, Odhiambo C, Mason L, Nyothach E, Oruko KO, Bauman A, Vulule J, Zeh C, Phillips-Howard PA (2016) Prevalence of reproductive tract infections and the predictive value of girls' symptom-based reporting: findings from a cross-sectional survey in rural western Kenya. Sex Transm Infect 92:251-256. https://doi.org/10.1136/sextrans-2015-052371

Köhler G, Milstein C (1975) Continuous cultures of fused cells secreting antibody of predefined specificity. Nature 256:495-497

Kolaskar AS, Tongaonkar PC (1990) A semi-empirical method for prediction of antigenic determinants on protein antigens. FEBS Lett 276:172-174. https://doi.org/10.1016/0014-5793(90)80535-q

Lewis WG, Robinson LS, Perry J, Bick JL, Peipert JF, Allsworth JE, Lewis AL (2012) Hydrolysis of secreted sialoglycoprotein immunoglobulin A (IgA) in ex vivo and biochemical models of bacterial vaginosis. J Biol Chem 287:2079-2089. https://doi.org/10.1074/jbc. M111.278135

Lewis WG, Robinson LS, Gilbert NM, Perry JC, Lewis AL (2013) Degradation, foraging, and depletion of mucus sialoglycans by the vagina-adapted Actinobacterium Gardnerella vaginalis. J Biol Chem 288:12067-12079. https://doi.org/10.1074/jbc.M113.453654

Marconi C, Donders GGG, Bellen G, Brown DR, Parada CMGL, Silva MG (2013) Sialidase activity in aerobic vaginitis is equal to levels during bacterial vaginosis. Eur J Obstet Gynecol Reprod Biol 167: 205-209. https://doi.org/10.1016/j.ejogrb.2012.12.003

Moncla BJ, Pryke KM (2009) Oleate lipase activity in Gardnerella vaginalis and reconsideration of existing biotype schemes. BMC Microbiol 9:78. https://doi.org/10.1186/1471-2180-9-78

Myziuk L, Romanowski B, Johnson SC (2003) BVBlue test for diagnosis of bacterial vaginosis. J Clin Microbiol 41:1925-1928. https://doi. org/10.1128/jcm.41.5.1925-1928.2003

Nugent RP, Krohn MA, Hillier SL (1991) Reliability of diagnosing bacterial vaginosis is improved by a standardized method of gram stain interpretation. J Clin Microbiol 29:297-301

Patterson JL, Stull-Lane A, Girerd PH, Jefferson KK (2010) Analysis of adherence, biofilm formation and cytotoxicity suggests a greater virulence potential of Gardnerella vaginalis relative to other bacterial-vaginosis-associated anaerobes. Microbiol Read Engl 156:392-399. https://doi.org/10.1099/mic.0.034280-0

Piot P, Van Dyck E, Peeters M, Hale J, Totten PA, Holmes KK (1984) Biotypes of Gardnerella vaginalis. J Clin Microbiol 20:677-679

Rodriguez-Walker M, Daniotti JL (2017) Human sialidase neu3 is Sacylated and behaves like an integral membrane protein. Sci Rep 7:4167. https://doi.org/10.1038/s41598-017-04488-w

Saha S, Raghava GPS (2006) Prediction of continuous B-cell epitopes in an antigen using recurrent neural network. Proteins 65:40-48. https://doi.org/10.1002/prot.21078

Schellenberg JJ, Paramel Jayaprakash T, Withana Gamage N, Patterson MH, Vaneechoutte M, Hill JE (2016) Gardnerella vaginalis subgroups defined by cpn60 sequencing and sialidase activity in isolates from Canada, Belgium and Kenya. PLoS One 11:e0146510. https:// doi.org/10.1371/journal.pone.0146510

Schneider CA, Rasband WS, Eliceiri KW (2012) NIH Image to ImageJ: 25 years of image analysis. Nat Methods 9:671-675. https://doi.org/ 10.1038/nmeth.2089

Smayevsky J, Canigia LF, Lanza A, Bianchini H (2001) Vaginal microflora associated with bacterial vaginosis in nonpregnant women: reliability of sialidase detection. Infect Dis Obstet Gynecol 9:1722. https://doi.org/10.1155/S1064744901000047

Sweet RL (2000) Gynecologic conditions and bacterial vaginosis: implications for the non-pregnant patient. Infect Dis Obstet Gynecol 8: 184-190. https://doi.org/10.1155/S1064744900000260

Thurman AR, Kimble T, Herold B, Mesquita PMM, Fichorova RN, Dawood HY, Fashemi T, Chandra N, Rabe L, Cunningham TD, Anderson S, Schwartz J, Doncel G (2015) Bacterial vaginosis and 
subclinical markers of genital tract inflammation and mucosal immunity. AIDS Res Hum Retrovir 31:1139-1152. https://doi.org/10. 1089/aid.2015.0006

Uhlen M, Bandrowski A, Carr S, Edwards A, Ellenberg J, Lundberg E, Rimm DL, Rodriguez H, Hiltke T, Snyder M, Yamamoto T (2016) A proposal for validation of antibodies. Nat Methods 13:823-827. https://doi.org/10.1038/nmeth.3995
Vidarsson G, Dekkers G, Rispens T (2014) IgG subclasses and allotypes: from structure to effector functions. Front Immunol 5:1-17. https:// doi.org/10.3389/fimmu.2014.00520

Publisher's note Springer Nature remains neutral with regard to jurisdictional claims in published maps and institutional affiliations. 